\section{Gilberto Gilvan Souza Oliveira}

Universidade Federal do Ceará (UFC)

\title{
Coleção Documentos Brasileiros: o Brasil em ensaios de história e interpretações sociológicas (1936-1989)
}

Brazilian Documents Collection:

Brazil in essays of history and sociological interpretations (1936-

1989)

\section{Resumo}

A Coleção Documentos Brasileiros, editada pela Livraria José Olympio Editora, foi lançada em 1936 com a publicação do livro Raízes do Brasil, de Sérgio Buarque de Holanda. O projeto em questão foi desenvolvido em três fases, com direção de Gilberto Freyre (1936-1938), Otávio Tarquínio de Sousa (1939-1959) e Afonso Arinos de Melo Franco (1960-1989). O presente artigo pretende discutir e analisar de que maneira a Coleção Documentos Brasileiros mobilizou e publicizou autores (literatos, historiadores, sociológicos, viajantes, críticos literários, entre outros) com o intuito de propiciar a compreensão e a interpretação do Brasil a partir do objeto livro. Esse anseio será perscrutado no escopo temporal de 1936 a 1989 , período que abrange a primeira e a última obra publicada com o selo da coleção.

Pallavras-chave: Coleção Documentos Brasileiros; Livraria José Olympio Editora; Narrativa.

\section{Abstract}

The Brazilian Documents Collection, edited by Livraria Tosé Olympio Editora, was launched in 1936, with the publication of the book Raízes do Brasil by Sérgio Buarque de Holanda. The project in question was developed in three phases, with direction of Gilberto Freyre (1931938), Otávio 'Taquínio de Sousa (1939-1959) and Afonso Arinos dé Melo Franco (1960-1989). This article intends to discuss and analyze how the Brazilian Documents Collection mobilized and publicized authors (literary, historians, sociologists, travelers, literary critics, among others) in order to propitiate the understanding and interpretation of Brazil from the book object. This yearning will be scrutinized in the temporal scope of 1996 to 1980 , period covering the first and the last work published white the seal of the collection in question.

Keywords: Brazilian Documents Collection; Livraria José Olympio Editora; Narrative. 

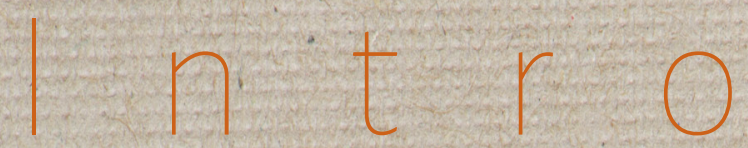

mabril de 1931, por incentivo de José Carlos de Macedo Soares, José Olympio comprou a biblioteca do advogado Alfredo Pujol, contendo em torno de 15 mil volumes. $\mathrm{Na}$ época, a biblioteca de Pujol era considerada a melhor biblioteca particular de São Paulo. Em seguida, adquiriu o acervo de Estêvão de Almeida, contendo uma vasta quantidade de obras raras como, por exemplo, a primeira edição do livro História Geral do Brasil (1854), de Francisco Adolfo Varnhagem. A aquisição das duas bibliotecas ocorreu por meio de empréstimos financeiros obtidos junto aos amigos.

Sete meses depois, em 29 de novembro do mesmo ano, foi fundada a Editora José Olympio, com a publicação da tradução do livro How to psychoanalyse yourself (Conheça-te pela Psicanálise), de ]. Ralph, feita por José Almeida de Camargo. Na edição do livro de Ralph, assim como em todos os jornais da cidade de São Paulo, estava lançado o convite para conhecer a nova editora da cidade:
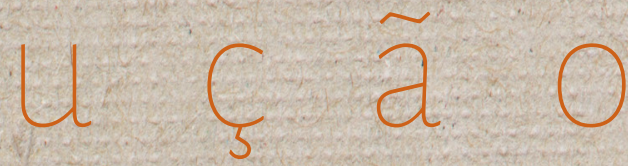

Nossa livraria vende os livros das bibliotecas que pertenceram aos bibliófilos e jurisconsultos Alfredo Pujol e Estêvão de Almeida. Nossa seção de livraria tem um variado sortimento de Direito, Filosofia, Clássicos, Brasiliana. Recebe da França as últimas novidades, toma a assinatura de jornais estrangeiros. Livraria José Olympio, Rua da Quitanda, 19-A, São Paulo (RALPH apud PEREIRA, 2008, p. 10).

Situada na Rua da Quitanda, 19-A, estava feita a aposta de José Olympio. Primeiro, se destacou por ter colocado seu próprio nome na editora, o que não era comum para a época ${ }^{1}$. Em pouco tempo, José Olympio atraiu os intelectuais que antes frequentavama Casa Carraux parasua Casa². Porém, sua temporada em São Paulo como editor foi breve. Em 1934, muda-se para o Rio de Jáneiro, onde inaugura a Livraria José Olympio Editora.

1 As principais livrarias do Rio de Janeiro durante as décadas de 1930 foram a Civilização Brasileira, Briguiet-Garnier, Livraria Acadêmica, Paulinas, Livraria Católica, Livraria Schmidt, Kosmos e a José Olympio. Já em 1940, o destaque foi para as livrarias Casa do Livro, Casa do Estudante do Brasil, Agir, Zahar (nesse caso, os irmãos Zahar), Livro Técnico, Vozes, Sodiler e Francisco Alves. Para um breve histórico sobre essas livrarias, ver Machado (2013).

2 Entre eles, podemos destacar Cassiano Ricardo, Mário de Andrade, entre outros. 
Em pouco tempo, José Olympio tornou-se o maior editor brasileiro, publicando trinta e dois livros em 1934; cinquenta e nove em 1935; e sessenta e seis títulos em 1936 (VILLAÇA, 2001, p. 78). Para o comércio do livro brasileiro dos anos 1930, esses números eram extremamente expressivos, tendo em vista que ainda não tínhamos um mercado editorial consolidado. Em 1961, ao completar trinta anos de funcionamento da editora, a soma das suas publicações chegou a duas mil trezentas e vinte e cinco edições.

Ao mesmo tempo, essa quantidade das publicações da Livraria José Olympio Editora criou o primeiro desenho de um mercado editorial no Brasil. Mas, como José Olympio conseguiu realizar tal feito? Segundo Nelson Werneck Sodré (1997, p. 72),

José Olympio, audacioso, sagaz, inteligente, compreendeu que estava começando a existir, no Brasil, já em proporções razoáveis, o mercado do livro, isto é, que o livro, além de uma função didática, começava a existir como mercadoria e a sua existência, assim, apresentava, agora, duplo aspecto: o cultural e o mercantil.

Ainda segundo Sodré, esta percepção de José Olympio estava estritamente ligada ao desenvolvimento do capitalismo no Brasil. É claro que, por se tratar de um livro de memórias, devemos, fazer algumas ressalvas quanto às declarações de Sodré, assim como nos alerta Sorá (2010).

Para Custavo Sorá (2010), foram as experiências editoriais vividas por Augusto Frederico Schimid, Gastão Cruls, Agripino Grieco e pelos editores da Livraria Adersen em publicar nov́os literatos que insuflaram em José Olympio interesses econômicos e culturais, visando expandir seus negócios e entrar na disputa editorial para editar obras cujo perfil era revelar um novo Brasil. Desta forma, as categorias de audacioso e sagaz não servem como ponto de partida para refletir sobre a experiência de José Olympio como editor.

No entanto, ao nos debruçarmos sobre a documentação da Livraria José Olympio Editora, podemos observar que o anseio de José Olympio era publicar livros que se propunham a (re)pensar o Brasil, o que tornou-se a principal característica da editora. Cabe destacar que ele estava partilhando do mesmo objetivo de outros editores, a exemplo 
de Monteiro Lobato com a Companhia Editora Nacional.

Um fator que contribuiu efetivamente para o sucesso da editora de José Olympio e fez com que ela se estruturasse foi o investimento na publicação dos romances de autores brasileiros e das obras que tinham como pretensão compreender e interpretar 0 Brasil ${ }^{3}$.

Para tanto, ele procurou estabelecer uma unicidade nacional na forma de uma coleção que, segundo Rodrigo Alves Ribeiro (2015, p. 175), tinha a incumbência de ampliar 0 acesso ao livro como objeto de estudo através da convergência da produção intelectual de autores novos e já consagrados, nacionalizando-se como "um produto editorial, pluralizando as conceituações de sociedade e cultu-

3 Dentre eles, Os sertões (1902), de Euclides dà Cunha, e Sagarana (1946), de João Guimarães Rosa. Já em relação às interpretações sociológicas e aos ensaios,de história, é possível elencar O outro Nordeste (1936), de Djacir Menezes, e Casa Grande e Senzala (1933) de Gilberto Freyre. ra". Faz-se importante mencionar que, em relação a esse último aspecto, José Olympio utilizou-se de uma política, editorial existente como, por exemplo, a Coleção Brasilianas, que vinha sendo publicada desde 1931 pela Companhia Editora Nacional.

Mas a tentativa do editor em pensar o Brasil não seria apenas a partir da literatura, gênero privilegiado em seu projeto editorial. Um exemplo disso é a Coleção Documentos Brasileiros, organizada primeiramente por Cilberto Freire. Além dissó, a José Olympio foi a primeira a publicar autores que tratavam de problemas locais, émbora sua pretensão fosse partir de temas regionais para compreender o nacional.

Desta maneira, os temas regionais transfiguraram-se no projeto editorial de maior demanda da José Olympio. Não foi à toa que ele deu atenção aos literatos modernistas e, em especial, aos autores que viriam a ser conheci- 
dos como pertencentes ao chamado ciclo nordestino, os quais foram seus principais editados.

Nosso objetivo com esse exercício reflexivo é pensar como a coleção de brasilianas de José Olympio possibilitou a construção de uma cartografia para o Brasil, utilizando como fontes os catálogos da editora, as obras lançadas com o selo da coleção e as notas críticas sobre seus títulos publicadas no jornal Correio da Manhã.

Em relação ao nosso escopo temporal, privilegiamos os anos de 1936 a 1989 , período que abrange a primeira e a última obra publicada na Coleção Documentos Brasileiros. Porém, é preciso considerar que o tema proposto é amplo e, em certa medida, nosso anseio é apresentar caminhos, vislumbrar possibilidades de discussões aprofundadas sobre as questões aqui expostas.

Quanto ao diálogo historiográfico, estamos partindo dos estudos de Eliane Dutra (2006) e Ciselle Venâncio (2007), que analisam as coleções de editoras brasileiras como a constituição de um acervo bibliográfico e documental para a história do Brasil; de Fábio Franzine (2006), que discute como as brasilianas da $J 0$ contribuíram para a formação da historiografia, brasileira; e de Rodrigo Ribeiro (2015) ao perscrutar as relações editoriais de José Olympio e seus editados, em especial com Cilberto Freyre.

\section{A Brasiliana de José Olympio}
Lúcia Miguel Pereira ${ }^{4}$ (1951, p. 11) considera que

a década de 30 foi extremamente fecunda para a literatura. Um sintoma econômico é frisante: ao passo que no começo do século os livros se editavam, na imensa maioria, na Europa, em Paris, pela Livraria Garnier, ,no Pôrto da Livraria Chardron, que, pouco antes, dera resultado comercial a corajosa iniciativa de Monteiro Lobato, ampliam-se agora as editoras já existentes e novas surgem. Escritores e mais escritores se revelando, chegando em boa parte das províncias, principalmente do Norte - lembra-se Manoel Bandeira "são os do Norte que vêm?". Basta percorrer a coleção do 'Boletim Ariel', mensário crítico - havia então lugar para

4 Lúcia Miguel Pereira se destacou por sua atuação como tradutora e crítica literária. A autora teve várias obras publicadas pela Livraria José Olympio Editora, entre elas, o livro História da Literatura Brasileira (1957), que compôs a Coleção Documentos Brasileiros. 
uma revista destinada tão somente à crítica - de Gastão Cruls e Agripino Grieco, para se verificar quanto foi rico o surto literário. [...] Refletindo a direção pelos escritores, os editores marcam a sua publicação pelas obras de pesquisa sobre o Brasil: a Companhia Editora Nacional faz a coleção "Brasilianas", a Livraria José Olympio - que lançou, com a editora fugaz do poeta Augusto Frederico Schmidt, a maior parte dos autores dessa época - a coleção "Documentos Brasileiros", a Livraria Martins a "Biblioteca Histórica"

Em seu um balanço sobre a produção literária no Brasil durante a primeira metade do século XX, Lúcia Miguel Pereira levanta alguns elementos interessantes para as nossas reflexões. Primeiro, que José Olympio, desde a fundação de sua editora, dedicou-se a publicar livros de autores brasileiros, em especial os escritores nordestinos. O primeiro a ser editado foi José Lins do Rego. Depois veio Rachel de Queiroz, Graciliano Ramos, e assim em diante.

O fato de José Olympio investir na publicação em grande escala da literatura brasileira que vinha sendo produzida desde o final da década de 1920 e início de 1930 , fazia parte de um projeto maior: o desejo da José Olympio Editora de publicar obras que tinham como pretensão interpretar e compreender o Brasil a partir de temas e de assuntos regionais.

No entanto, nesse aspecto, o projeto da José Olympio Editora diferenciava-se principalmente dos projetos editoriais da Liuraria Martins e, em certa medida, da Companhia Editora Nacional, apesar da José Olympio também ter publicado as brasilianas pertencentes à biblioteca de Alfredo Pujol - as quais, unidas às obras de filosofia, direito, livros estrangeiros e dos autores nacionais ligados ao movimento literário modernista, foram um dos principais chamarizes da J.O. nos primeiros anos de sua atuação no mercado dos livros.

Antes de avançarmos nessas discussões sobre os distanciamentos e aproximações dos projetos das três editoras, é preciso refletir sobre o conceito de Brasilianas. Para Nelson Werneck Sodré (1942), todas as obras que tinham como pretensão interpretar a história brasileira poderiam ser incluídas nesta categoria. As brasilianas contariam e interpretariam a história do Brasil a partir de vários gêneros textuais e formas editoriais. Essa consideração de Sodré consta em duas obras do au- 
tor: Orientações do pensamento brasileiro (7942) e O que se deve ler para conhecer o Brasil (1945) - a segunda, já significativa e sugestiva pelo próprio título.

Nelson Werneck Sodré tentou oferecer ao leitor um conjunto de fontes para o estudo da História do Brasil. Ao longo das edições de $O$ que se deve ler para conhecer o Brasil (1945), o autor fez alterações sistemáticas: retirou e adicionou referências bibliográficas e produziu prefácios explicando os motivos dessas alterações. No prefácio à primeira edição, o tom de escrita foi mais uma denúncia do que uma explicação formal sobre a obra.

Para ele, o número de publicações em língua portuguesa sobre a História do Brasil era incipiente. Seria necessário que os editores investissem em traduções de obras cujo objeto de estudo ou de relato fosse a cultura brasileira. No prefácio à quinta edição o o tom muda completamente. Nessa versão, Werneck Sodré ressalta o desenvolvimento do mercado editorial brasileiro por ter publicado uma série de obras sobre o Brasil.

5 A primeira edição é de 1945 , a segunda de 1960 e sexta edição de 1976. Quanto às datas da terceira, da quarta e da quinta edição, não conseguimos identificar.
O autor refere-se, mesmo que indiretamente, às coleções das editoras José Olympio, Martins e Companhia Nacional, basta consultar as referências indicadas por ele. Apesar de reconhecer o fenômeno editorial como positivo, Werneck Sodré, para dar crédito de relevância à sua obra, destaca que, naquele momento, a necessidade seria a existência de trabalhos de síntese sobre a cultura brasileira. Talvez ele estivesse dizendo que seu livro, em certa medida, preenchia essa lacuna, já que era essa a sua pretensão.

Em geral, as brasilianas se caracterizavam por apresentar ao leitor uma interpretação do passado nacional por meio do diálogo com estudos e prefácios feitos por intelectuais contemporâneos às novas edições. Para Heloisa Pontes (1988, p. 69), as coleções produzidas por essas editoras

caracterizavam-se pela edição de autores representativos do período e pela reedição de autores nacionais e estrangeiros, principalmente viajantes. Semelhantes em vários aspectos, temáticos e formais, apresentavam uma estrutura geral similar ao "modelo euclidiano" de apreensão da realidade, tal como aparece em Os Sertões. Isto é, trata-se de uma produção centrada sobretudo na caracterização da 
Terra (leia-se geografia, biologia, botânica, arqueologia), do Homem (viajantes e cronistas, antropologia e etnologia, folclore, memórias, etc.). A Luta, por sua vez, refere-se menos aos aspectos conflitivos da história brasileira, e mais à tensão que se pode detectar [...] entre os ensaios de interpretação sobre o Brasil e os ensaios historiográficos.

As coleções quando reunidas, apesar de suas diferenças, constituíam-se como um acervo bibliográfico para o entendimento do que seria o Brasil. Com um caráter documental, o que estava em questão era o conceito de história, mesmo que suas tipologias textuais fossem as mais diversas.

Contudo, elas podem ser analisadas por outro ângulo. Eliane de Freitas Dutra (2006, p. 300) considera que essas coleções de brasilianas podem ser compreendidas como a constituição de uma biblioteca ideal, ou uma enciclopédia que seleciona, classifica, acumula e ordena, cujo padrão editorial, por um lado, adveio da "concepção iluminista do progresso social, assentado na nacionalidade, no conhecimento e nos livros, e, de outro, impulsionados pelos ventos favoráveis das políticas educacionais, [...] as coleções se afir- maram como um modelo atraente e rentável".

A primeira coleção de brasilianas a circular no Brasil foi a da Companhia Editora Nacional. Segundo Gustavo Sorá (2010, p. 161), ela popularizou, entre um público leitor interessado pela definição de um caráter nacional, os ensaios de interpretação da história e da realidade brasileira, tornando-se "um prolongamento do projeto nacionalista que orientava a percepção e as escolhas dos donos e assessores culturais, plasmado no próprio nome da Companhia".

Ainda segundo Sorá (2010), esse projeto da Companhia Editora Nacional estabeleceu um modelo para outras editoras que publicariam obras cuja intenção era interpretar o Brasil. O primeiro volume da Coleção Brasiliana foi lançado em 1931. Tratava-se do livro Figuras do Império e Outros Ensaios, de Antônio Pereira Batista.

Segundo Giselle Martins Venâncio (2007, p. 53), a coleção Brasilianas, "fazia parte, incialmente, de um projeto editorial mais complexo lançado pela Companhia Editora Nacional, que se 
intitulava Biblioteca Pedagógica Brasileira", organizada por Fernando de Azevedo.

Em 1940, quatro anos depois da primeira obra publicada pela Coleção Documentos Brasileiros da José Olympio, foi lançado o projeto editorial Biblioteca Histórica Brasileira da Livraria Martins Editora, de São Paulo, cuja direção foi de Rubens Borba Moraes ${ }^{6}$.

Em resenha escrita para o jornal Correio da Manhã de 29 de fevereiro de 1940, Carlos Maui destaca a importância da coleção Biblioteca Histórica Brasileira, afirmando que ela traria ao leitor que gostava de história e aos historiadores um rico material sobre - Brasil. Para tanto, ele utiliza o livro Viagem Pitoresca através do Brasil, de Johann Moritz Rugendas, para embasar seu argumento. A tradução do livro de Rugendas, feita por Sérgio Millet, foi o primeiro volume da coleção.

Segundo a resenha feita por Maui, Viagem Pitoresca sobre o Brasil se tratava de uma grande obra que possuiu poucos exemplares em sua primeira edição

6 Moraes era bibliófilo, diretor da Escola de Biblioteconomia, anexa a Escola Livre de Sociologia e Política de São Paulo, e professor das disciplinas de Bibliografia e História do Livro. e, por isso, para o resenhista, existia a necessidade de uma nova edição, pois somente bibliófilos e museus possuíam algum exemplar. Ele continua o texto dizendo que a riqueza da obra estava no conjunto de imagens produzidas por Rugendas durante sua viagem ao Brasil entre 1827 a 1835 . Os resultados dessa viagem foram publicados primeiramente em alemão e em francês no ano de 1935. Nesse sentido, a edição em português de

"Viagem Pitoresca ao Brasil", deixa[va] de ser uma coleção de imagens para a contemplação tranquila dos bibliômanos, para se tornar leitura instructiva e edificante dos que vêem na história, em qualquer das suas modalidades, o espelho da continuidade dos povos que se transformaram mas não desapareceram (MUAl; 1940, p. 4).

Mais do que pelos textos, a Biblioteca Histórica Brasileira ficou conhecida por apresentar uma série de imagens feitas do Brasil. Para Stickel (2014), ao publicar a reprodução de um conjunto de gravuras originais de viajantes que vieram ao Brasil, a coleção contribuiu para a formação de um conjunto iconográfico sobre o país. Hoje essas publicações se tornaram fonte fecunda para os estudos históricos. 
Assim, a coleção, que fora voltada e elaborada especialmente para bibliófilos e interessados pelos estudos brasileiros, ficou conhecida por reedições e traduções de textos de viajantes que vieram ao Brasil, adicionada de prefácios de intelectuais como, por exemplo, José Honório Rodrigues e Sérgio Millet.

O nome de Affonso de E. Taunay destaca-se entre os prefaciadores da coleção em questão. Outras obras foram reeditadas pela Biblioteca Histórica Brasileira como, por exemplo, História da Missão dos Padres Capuchinhos na Iltha do Maranhão, de Claude d'Abeville; Diário de minha viagem ao Brasil, do Príncipe Adalberto da Prússia; Imagens do Brasil, de Carl Von Koseritz; Notas sobre o Rio de Janeiro e partes meridionais do Brasil, de John Luccok; e Brasil Pitoresco, de Charles Ribeyralles.

Affonso de E. Taunay também prefaciou as obras Igrejas de São Paulo (Introdução ao estudo dos tempos mais característicos de São Paulo nas suas relações com a crônica da cidade), de Leonardo Mota Arroyo, publicada em 1954; Ensaio sobre a história política e administrativa do Brasil'(1500-7810), de Rodolfo Carcia, lançada em 1956; e também publicou seu livro Agrande vida de Fernão Dias Pais (1955), todas pela Coleção Documentos, Brasileiros da José Olympio Editora. Esses elementos revelam que, mesmo com as suas diferenças, as coleções que visavam compreender e interpretar o Brasil tinham suas proximidades e semelhanças.

Já as brasilianas da José Olympio, intituladas como Coleção Documentos Brasileiros, foram lançadas em 7936. Os primeiros dezoito volumes da coleção foram dirigidos por Gilberto Freyre, os demais por Otávio Tarquínio de Souza e, em seguida, por Afonso Arino de Melo Franco. Pela coleção foram lançados 207 títulos, distribuídos entre obras de biografias, memórias, história, folclore, etnologia, geografia e crítica literária.

A primeira obra publicada pela Coleção Documentos Brasileiros foi Raízes do Brasil (1936), de Sérgio Buarque de Holanda: No prefácio à primeira edição deste livro, Cilberto Freyre nos indica uma característica da José Olympio: publicar literatura e documentos. Para Cilberto Freyre (1936 apud PEREIRA, 2008, p. 412), Sergio Buarque de Holanda era 
o autor que melhor exprimia "não só o desejo como a capacidade de analisar, o gosto de interpretar, a alegria intelectual de esclarecer". Daí o motivo da escolha do autor para lançar a coleção e a sua relação com as principais características do projeto: analisar, interpretar e esclarecer.

Ainda no prefácio à primeira edição de Raízes do Brasil é possível identificar que outra preocupação da coleção era a objetividade das obras e a publicação de documentos inéditos. Gilberto Freyre, nos primeiros volumes da coleção, buscou selecionar interpretações sociológicas em forma de ensaios. Para ele, o projeto de José Olympio

Não se trata[va] de uma aventura editorial, mas de uma coleção planejada e organizada com maior escrúpulo e com todo o vigor, visando corresponder não só às necessidades do estudioso como à curiosidade intelectual de todo brasileiro pelas coisas e pelo passado do seu país (FREYRE, 1936 apud PEREIRA, 2008, p. 412).

Diferente das outras coleções, em que seus primeiros números trataram apenas do pretérito, o primeiro volume da coleção da José Olympio, além de estudar o passado brasileiro, buscou compreender a sua contemporaneidade,
- tempo presente da publicação da obra. Nesse caso, leia-se por contemporaneidade os anos de 1930, a mesma década de produção e lançamento do livro de Sérgio Buarque.

Sérgio Buarque de Holanda, no livro Raízes do Brasil, propõe uma ruptura com determinados antecedentes do passado brasileiro. Ao mesmo tempo, a Livraria José Olympio Editora dava seus primeiros passos para instituir uma nova ordem de produção de livros no Brasil, tanto no que se refere aos projetos editoriais, quanto em suas tipologias literárias. Dessa forma, há uma harmonia, uma consonância entre o projeto da editora e o exercício interpretativo do autor, e um distanciamento, uma diferenciação das brasilianas publicadas pela Companhia Editora Nacional'e a Martins.

É importante mencionar que a Coleção Doćumentos Brasileiros publicou diários de viajantes, como fizeram as outras duas coleções que aqui foram analisadas brevemente? Porém, ela se dedicou a publicar estudos contem-

7 Sobre os diários de viagens, nos referimos às obras: Paraná Vivo (Um retrato sem retoques), de Temístocles Linhares (1953); Os Sertanejos que eu conheci, de Frei José M. Audrin (1964); Viagem ao país dos paulistas, de Ernânni Silva Breno (1966); Novo Caminho do Brasil Meridional (Três anos de vida em florestas e campos, 1872-1875), de Thomas P. Bigg-Wither (1974), entre outros. 
porâneos sobre o passado e obras que tratavam dos problemas brasileiros à época. Essa coleção foi um dos projetos, talvez o maior deles, que tinha como principais adjetivos a modernidade e a contemporaneidade, sendo as memórias e as autobiografias os gêneros que obtiveram números expressivos de edições.

Quando a Coleção Documentos Brasileiros estava sob a direção de Tarquínio de Sousa, foram publicadas as obras História da Literatura Brasileira (Seus fundamentos econômicos), de Nelson Werneck Sodré, em 1940; e História da Literatura Brasileira, dirigida por Silvio Romero, em 1943. Álvaro Lins também coordenou uma série de publicações intituladas História da Literatura Brasileira. Por essa última, foram lançadas História da Literatura Brasileira (Prosa e Ficção - de 7870 a 1920), escrita por Lúcia Miguel Pereira, em 1950, e História da Literatura Brasileira (Literatura Oral), de Luís Câmara Cascudo, de 1952, entre outras.

É interessante perceber que a maioria das publicações descritas como história restringia seu recorte temporal o mais próximo possível do ano de sua publicação, como é caso de Lúcia Miguel Pereira, que estudou a prosa e a ficção de 1870 a 1920, cujo estudo foi publicado em 1950 . O mesmo aconteceu com o estudo de Luiz Heitor, publicado no livro 750 anos de Música no Brasil (1800-1950), em 1956. Dessa forma, os recortes temporais das publicações indicavam a sua atualização.

Nesse sentido, para compreender e interpretar a nação brasileira seria necessário, além de estudar o passado, refletir sobre o presente. Sendo assim, os livros de memória e as autobiografias, em diálogo com os recortes cada vez mais próximos da data de publicação das obras, contribuíam para caracterizar a coleção como moderna e contemporânea.

Portanto, o que se colocava em questão era o entendimento de um passado que ainda se fazia presente, de um pretérito em movimento, tendo em vista que, para o caso das memórias e das autobiografias, em sua maioria, os autores estavam vivos. Contudo, podemos auferir que existia um entrelaçamento entre passado distante, modernidade e contemporaneidade.

Outro aspecto importante para ser 
analisado é a forma como essas coleções de brasilianas foram divulgadas. Ao contrário do caso da Martins Editora, cuja diferença se encontra no conteúdo e no público, um dos aspectos que distanciava a Livraria José Olympio Editora da Companhia Editora Nacional foram as formas de divulgar e publicizar as obras. Mesmo quando se tratava de obras que, ao serem lançadas, continham o selo da José Olympio e possuíam como abordagem o passado brasileiro, estavam precedidas das palavras moderna e contemporânea ao serem divulgadas.

Maria Odila Dias (2013, p. 22), ao se referir à produção historiográfica de Caio Prado Júnior, destaca que, para ele, os "fatos e eventos teriam pouco sentido a não ser quando trabalhados como parte de um movimento, do processo dialético, envolvendo movimentação, tendências contraditórias, diferentes sentidos". Em certa medida, a José Olympio Editora publicou obras que constituíram um movimento dialético entre aproximações e distanciamentos, conflitos e diálogos entre autores, temas e conteúdos.

Ao mesmo tempo em que a editora es- tabelecia esse modelo dialético de publicação de livros, também inseria as obras em um jogo de temporalidades. Essas, por sua vez, estabeleceram-se por meio de deslocamentos, aprisionamentos e (re)inserção dos exemplares em novos modelos editoriais. É o caso das décadas de 1950 e 1960, em que há um retorno aos escritores do século XIX, a exemplo das reedições dos livros de José de Alencar.

A reedição dessas obras, além de fatores editoriais, foi motivada pela "bipolarização que a historiografia irá implantar entre os ditos modernistas e tradicionalistas, existiam pontos de convergência entre os escritores de então: o interesse de interpretar o país e a José Olympio" (RIBEIRO, 2015, p. 173). Além disso, cabe destacar que é nesse período que surgem os primeiros resultados das produções acadêmicas no país e o interesse em pesquisas das obras dos escritores e da história da literatura.

Em relação aos aprịionamentos temporais, podemos elencar, para deixar essa consideração mais clara, a Coleção Obras Reunidas, que foi elaborada para vários autores editados pela José 
Olympio Editora. Mas, embora haja um aprisionamento, o fechamento de um ciclo por meio da coleção, as obras continuavam em movimento, dentro de um jogo criativo de estabelecimento de um cânone e da ampliação e formação de um novo público leitor.

Tomemos para análise as Obras Reunidas de Cilberto Freyre. Nos anúncios publicitários sobre o livro Olinda, publicado na coleção em 1960, o destaque era para as seguintes informações que foram escritas em caixa alta: revista, atualizada e aumentada. Se de um lado as obras reunidas estavam encerrando um ciclo, consolidando e reconhecendo uma trajetória intelectual, por outro elas inseriam as obras do autor numa nova temporalidade.

Ao ser revista, atualizada e aumentada, a reedição é introduzida no tempo presente, sendo capaz de limpar a poeira que havia sido acumulada pelo passado. Tal poeira foi amontoada devido às ruínas provocadas pela crítica, pelo amadurecimento intelectual do autor. Uma nova obra surge, mas esse novo não é uma novidade, é um diálogo entre o pretérito e o.presente, é a possibilidade de um futuro, de uma nova trajetória em consonância com os caminhos já percorridos.

Outro aspecto das publicações da José Olympio Editora era o regime de visualidade criado para os livros. Se nas edições anteriores - para o caso de autores que já possuíam obras publicadas sem o selo da 7.0. - as únicas imagens existentes nos exemplares eram aquelas criadas pela escrita, nas reedições essas imagens passam a ser capturadas pelas mãos e pinceis do seleto grupo de artistas que ilustravam os livros publicados pela editora. Nesse time, figuravam os nomes como o de Tomás Santa Rosa, Candido Portinari e Eugênio Hirsch.

O cuidado com as ilustrações refletiu-se principalmente nas capas dos livros. Houve uma supervalorização dos recursos visuais empregados na éncadernação, afinal ela é o primeiro contato físico que o leitor estabelece com uma obra. Esse regime de visualidade possuía uma estética caracterizada por desenhos feitos à mão e clichês da assinatura dos autores. É o caso da $12^{a}$ edição do romance $O$ Quinze de Rachel de Queiroz. 
A edição supracitada contou com uma série de ilustrações feitas por Poty ${ }^{8}$, cuja estética seguiu o modelo de produção de imagens sobre a seca no Nordeste. Nesse sentido, o artista, inserido dentro do regime de visuali- grandes autores da literatura brasileira" (MELO, 2011, p. 276). No caso do romance de Rachel de Queiroz, o desenhista elaborou suas gravuras com o intuito de conectá-las ao texto, conforme podemos perceber a seguir:

Figura 1 - Ilustrações feitas por Poty para compor o projeto gráfico da $12^{a}$ edição d’ O Quinze.
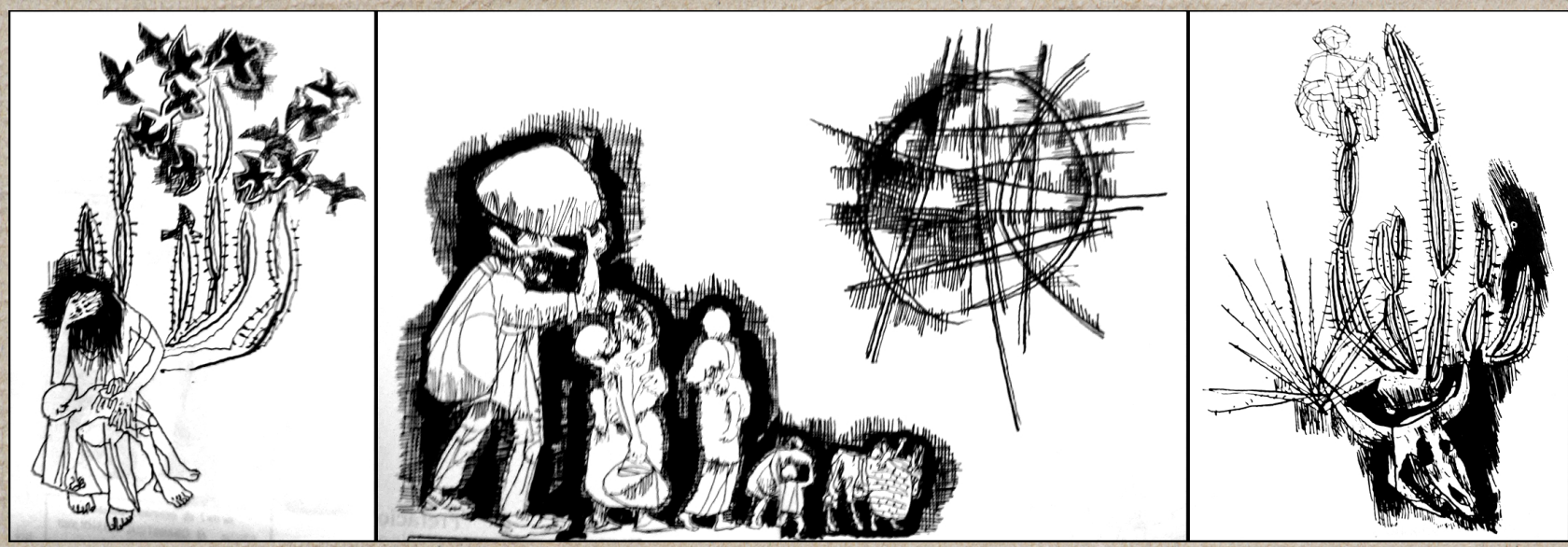

Fonte: Queiroz (1970).

dade para a produção de livros da José Olympio, partiu dos tropos narrativos e da tropologia visual sobre a seca para compor o seu fazer enquanto ilustrador.

É importante destacar, também, que "Poty ocupou lugar de honra no elenco dos artistas-ilustradores-designers que atuaram no campo editorial. Ele inicia nessa década [lê-se anos 1950] sua obra como ilustrador maiúsculo de

8 Assim era chamado o artista Napoleon Potyguara Lazzarotto. Poty foi ilustrador de jornais, revistas e livros. Formado pela Escola Nacional de Belas Artes, no campo da arte atou como desenhista e gravurista, cuja especialização era a litrografia. Na década de 1980, foi considerado um dos maiores artistas do país. Ver Barata (1984).
As três ilustrações (Figura 1) fazem referência a momentos distintos da narrativa do romance $O$ Quinze. A primeira traz o sofrimento da personagem Cordulina ao perder seu filho, Josias, que havia morrido por inanição. A segunda imprime a caminhada, a retirada da família de Chico Bento da cidade de Quixadá até Fortaleza. Já na terceira, o artista se detém a capturar em primeiro plano a imagem da vegetação e, ao fundo, a do vaqueiro. Possivelmente, em relação a esse último apontamento, foi realizada uma referência a Vicente, que no romance 
decide permanecer no sertão mesmo com a seca.

Sobre essa última observação, o recurso visual reforça outra imagem criada pela literatura em relação ao homem que vive no campo. Vicente representa a força, a valentia e a bravura do sertanejo que mesmo com todas as dificuldades existenciais não abandona a sua terra. Decide permanecer enquanto houver juazeiro e mandacaru em pé.

Além disso, tais ilustrações também remetem a duas passagens da narrativa bíblica: a descrição do evangelista João sobre o momento em que Maria chora pela morte de seu filho Jesus, ea fuga de Maria e José para Egito, descrita no evangelho de Mateus. Estas, por sua vez, corresponderiam ao choro de Cordulina devido à morte de Josias e 0 traslado realizado pela família do interior à capital.

Ao mesmo tempo em que essas imagens dão corpo e forma ao texto do romance, é possível tratá-las como um recurso que insere o livro de Rachel de Queiroz dentro de uma cultura visual que não se restringe apenas à relação entre texto e imagem, mas também o relaciona intimamente ao imaginário social sobre a seca; fazendo dessa inserção uma possibilidade de leitura tanto para os letrados quanto para os não letrados.

Segundo Mário Barata (1984, p. 30), a incursão de Poty na arte figurativa e as suas composições das séries de sequências temáticas são caracterizadas pela presença do "signo ou do drama da brasilidade, em sentido nativista, que desde as gravuras (1955) para Canudos de Euclides da Cunha vinha estruturando uma das bases de sua personalidade". Nesse sentido, podemos considerar que, no caso d'O Quinze de Rachel de Queiroz, há uma sintonia entre escritor (narrativa textual), autor (a obra), ilustrador e os elementos constitutivos do livro com o desejo da José Olympio de compreender e interpretar o Brasil.

A valorização da estética não estava presente somente nas ilustrações, na diagramação, enfiṃ no projeto gráfico. Aqui cabe retornar ao texto de Lúcia. Miguel Pereira no tocante à publicação de obras cujo estilo e forma de escrita estavam vinculados aos temas 
regionais. Como é sabido, a escrita re- José Olympio possui uma diferengionalista, principalmente o chamado ça latente entre os projetos de José romance social, tinha como marca o tom de denúncia dos problemas locais como, por exemplo, para o caso do Ceará, a seca.

Va José Olympio Editora, esses textos foram tratados e considerados mais por seu valor estético do que pelo seuvalor político. Afinal, o projeto da

Na José Olympio Editora, esses textos foram tratados e considerados mais por seu valor estético do que pelo seu valor político. Afinal, o projeto da editora de compreender e interpretar o Brasil passava. pela dimensão de que as fronteiras necessitariam ser fluídas ou borradas, ou seja, elas editora de compreender $e$ interpretar o Brasil passava pela dimensão de que as fronteiras necessitariam ser fluídas ou borradas, ou seja, elas deveriam existir superficialmente ou'já que existiam, careceriam ser tratadas como uma costura que junta os retalhose forma um único tecido. de Barros Martins e Octalles Marcondes Ferreira, responsáveis pela Martins Editora e pela Companhia Editora Nacional, respectivamente. Diferente das coleções de brasilianas das outras editoras, José Olympio estabeleceu diálogos com outros gêneros literários. Nesse caso, a publicação da literatura regionalista, mesmo não contendo a marca tipográfica da Coleção Documentos Brasileiros, inventava e fazia parte do condeveriam existir superficialmente ou, já que existiam, careceriam ser tratadas como uma costura que junta os retalhos e forma um único tecido. Sendo assim, não haveria fronteiras fixas, sólidas. Era o conjunto de toda a literatura regionalista e outras literaturas juntas que daria um sentido e uma forma à nação brasileira.

É nesse ponto que a proposta de junto de obras que proporcionavam aos leitores a compreensão do que seria a história do Brasil.

Partindo do espectro que os livros (textos, elementos materiais e simbólicos) são capazes de inventar a história por meio da consolidação de narrativas, outro empreendimento editorial de grande sucesso da José Olympio foi a Coleção Sagarana. Semelhante à Coleção 
Documentos Brasileiros, no que se refere ao conteúdo das obras, ela tinha como objetivo publicar os grandes sucessos populares para instruire distrair o leitor.

\section{É importante realizar algumas obser-} vações sobre a referida coleção. Para Rodrigo Ribeiro (2015, p. 273-274), ela pode ser considerada como uma tentativa de ir ao encontro de leitores atentos que "intencionam encontrar na literatura parte, ou o todo, do que são [...] como brasileiros".

Ainda segundo o autor, a escolha dos autores que comporiam a coleção estava ligada às discussões realizadas no Conselho Federal de Cultura (CFC) que, naquele momento, exercia forte influência nas políticas culturais do país, em especial por conta da participação de Gilberto Freyre, então editor e autor da José Olympio.

Mas, o que nos aproxima das discussões de Rodrigo Ribeiro (2015) é o limiar de analisar a coleção como um meio de compreensão do que é o Brasil e, portanto, do que são os brasileiros. Podemos considerar que a descoberta do país foi pensada a partir de um mosaico, algo extremamente simbólico e dialógico, como a primeira edição da obra Sagarana, de Guimarães Rosá, pelo sinete da José Olympio, lançada em 1956 com ilustrações de Poty?

A capa da edição feita pelo ilustrador é formada por figuras de círculos que estão soltos, "desenhados ao modo carimbos, [que] condensa a atmosfera de uma das histórias - ou estóreas, como preferia Cuimarães Rosa" (MELO \& COIMBRA, 2011, p. 275). O texto roseano, assim como o frontispício do livro, é formado por contos narrativamente independentes, mas que possuem interseções entre si.

Desse modo, a obra de Guimarães Rosa torna-se a metáfora geradora para a coleção de José Olympio e o seu desejo de compreender e interpretar o Brasil. Cada publicação que compunha a coleção poderia ser tratada como uma história, ou parte da história do país. Estas obras, por sua vez, trariam ao leitor um aspecto, ou problema da realidade brasileira e, juntas, numa espécie de mosaico das diferenças, oportunizariam ao leitor $\mathrm{o}$ conhecimento da brasilidade.

Porém, apesar das diferenças em sua

9 Cabe destacar que o projeto da Coleção Sagarana foi elaborado, incialmente, para homenagear João Guimarães Rosa e tinha como pretensão de publicar obras de autores nacionais e estrangeiros. Contudo, privilegiou os escritores brasileiros e o gênero romance. 
composição, a Coleção possuía um fluxo irradiador: o sertão. Embora a narrativa roseana estivesse se referindo ao sertão das Minas Cerais, e o projeto editorial da José Olympio ao da região nordeste, elas confluíam e se cruzavam a partir do momento que a escoIha deu-se em pensar o Brasil através das bordas (leia-se, o interior do país) e não do centro (o eixo Rio - São Paulo). Desse modo, o nordeste e o sertão ocuparam lugares de destaque nos projetos editoriais que foram elaborados pelo grupo da $] .0$.

Nesse sentido, as interpretações sociológicas, os ensaios de história e os romances, entre eles $\mathrm{O}$ Quinze, de Rachel Queiroz, que foi tomado como chamariz para compreender a seca no Nordeste, bem como os demais autores que figuram na coleção, a exemplo do próprio Cuimarães Rosa (com Sagarana e Noites no Sertão) e José Lins do Rego (com Menino de Engenho, Fogo Morto, Moleque Ricardo, Eurídce e Banguê), apresentavam outros cenários brasileiros.

\section{Considerações finais}

A partir das discussões realizadas, é possível auferirmos que José Olympio partiu da experiência de outros editores para criar e consolidar seu selo no mercado editorial brasileiro. Seu projeto não se consolidaria caso se restringisse apenas às coleções formadas com estudos de sociólogos, historiadores, entre outras especialidades.

Era preciso estabelecer o diálogo com outros campos. Foi o conjunto variado de gêneros textuais, formas editoriais e estratégias de produção e circulação das obras, a força motriz de seu sinete. Sendo assim, por exemplo, o livro Raízes do Brasil, de Sergio Buarque de Holanda, e O Quinze, de Rachel de Queiroz, não estavam um acima do outro.

A História, a crítica literária e a Literatura deram fôlego ao desejo da José Olympio em produzir uma nova interpretação sobre o Brasil. Afinal, se os intelectuais ligados à academia preferiam Raízes do Brasil, o público leitor mais amplo escolheria ler um livro de literatura genuinamente nacional numa tarde de domingo.

Desse modo, entender como a José Olympio estabeleceú uma cartografia para que os leitores pudessem conhecer o território brasileiro é refletir, ao mesmo tempo, sobre as políticas editoriais e a consolidação do mercado 
editorial no Brasil. Contudo, devemos atentar para o fato de que as discussões aqui apresentadas podem ser tidas como um sopro para aprofundamentos e a possibilidade de novas pesquisas sobre o tema em questão.

\section{Referências:}

BAPTISTA, Antônio Pereira. Figuras do império e outros ensaios. São Paulo: Companhia Editora Nacional, 1931.

BARATA, Mário. Poty: a arte contra a guerra. Revista do Brasil, Rio de Janeiro, v. 1, n. 2, p. 28-32, 1984.

DIAS, Maria Odila Leite da Silva. Caio Prado Jr: dialética da experiência histórica. In: NOCUEIRA, Antonio Gilberto Ramos; CONÇALVES, Adelaide (Orgs.). Caio Prado Jr. legado de um saber histórico. São Paulo: Hucitec, 2013. p. 17-38.

DUTRA, Eliana de Freitas. A nação nos livros: a biblioteca ideal na coleção Brasiliana. In: DUTRA, Eliana de Freitas; MOLIER, Jean-Yves (Orgs.). Política, nação e edição: o lugar dos impressos na construção da vida política no Brasil, Europa e Américàs nos séculos XVII-XX. São Paulo: Annablume, 2006. p. 299-3.74.

FRANZINE, Fábio. À sombra das palmeiras: a Coleção Documentos Brasileiros e as transformações da historiografia nacional (1936-1959). 2006. Tese (Doutorado em História Social) - Universidade de São Paulo, São Paulo. 2006.

FREYRE, Gilberto. Casa-Crande e Senzala: formação da família brasileira'sob o regime da economia patriarcal. 20. ed. Rio de Janeiro: Livraria José Olympio Editora, 1950.

HOLANDA, Sérgio Buarque de. Raízes do Brasil. 14. ed. Rio de Janeiro: Livraria José Olympio Editora, 1987.

MACHADO, Ubiratan. História das Livrarias Cariocas. São Paulo: Edusp, 2013.

MELO, Chico Homem de; COIMBRA, Eliane Ramos (Orgs.). Linha do tempo do design gráfico no Brasil. São Paulo: Cosac Naify, 2011.

MENESES, Djacir. O outro Nordeste: ensaios sobre a evolução social e política do Nordeste da "civilização do couro" e suas implicações históricas nos problemas gerais. 3. ed. Fortaleza: Casa José de Alencar/Programa Editorial, 1995.

MAUI, Carlos. Viagem pitorescà através do Brasil. Correio da Manhã, Rio de Janeiro, 29 fev. 1940, p. 4. 
PEREIRA, José Mário (Org). José Olympio: o editor e a sua casa. Rio de Janeiro: Sextante, 2008

PEREIRA, Lúcia Miguel Cinquenta anos de Literatura. Correio da Manhã, Rio de Janeiro, 15 de jun. 1951. Caderno Cultura Brasileira, p. 11

. História da Literatura Brasileira: prosa e ficção (1870-1920). 2. ed. Rio de Janeiro: Livraria José Olympio Editora, 1957.

PONTES, Heloisa. Retratos do Brasil: um estudo dos editores, das editoras e das "Coleções Brasilianas" nas décadas de 1930, 40 e 50. BIB-Revista Brasileira de Informação Bibliográfica em Ciências Sociais, Rio de Janeiro, n. 26, p 56-89, jun./dez. 1988.

QUEIROZ, Rachel de. O Quinze. Rio de Janeiro: Livraria José Olympio Editora, 1970.

RALPH, J. Conheça-te pela psicanálise. São Paulo: José Olympio Editora, 1931.

RIBEIRO, Rodrigo Alves. "Revele, pois, a falta de minhas respostas..." interfaces entre as cartas e os livros de Gilberto Freyre (1933-1978) . 2015. Tese (Doutorado em História)-Universidade Federal do Ceará, Fortaleza. 2015.

ROSA, João Guimarães. Sagarana. Rio de Janeiro: Livraria José Olympio Editora, 1958.

SODRÉ, Nelson Werneck. História da Literatura Brasileira (Seus fundamentos econômicos). Rio de Janeiro: Livraria José Olympio Editora, 1940.

. Orientações do pensamento brasileiro. Rio de Janeiro: Livraria José Olympio Editora, 1942.

. O que se deve ler para conhecero Brasil. Rio de Janeiro: Livraria José Olympio Editora, 1945.

Memórias de um escritor I. Rio de Janeiro: Civilização Brasileira, 1997.

SORÁ, Gustavo. Brasilianas: José Olympio e gênese do mercado editorial brasileiro. São Paulo: Edusp; Com-Arte, 2010.

STICKEL, Erico ]. Sniuba. Uma pequena biblioteca particular: subsídios para o estudo da iconografia no Brasil. São Paulo: Edusp; Imprensa Oficial, 2014.

VENÂNCIO, Giselle Martins. Prefácio de Viana na coleção Brasiliana: estratégias de legitimação e construção da autoria. Locus-Revista de História, Juiz de Fora, v. 13, n. 2, p. 49-60, 2007.

VILLAÇA, Antônio Carlos. José Olympio: o descobridor de escritores. Rio de Janeiro: Thex, 2001. 
